\title{
The Home Literacy Environment of Preschool-Age Children with Autism or Down Syndrome
}

\author{
Marleen Westerveld ${ }^{a, b} \quad$ Anne K. van Bysterveldt ${ }^{c}$ \\ ${ }^{a}$ Cooperative Research Centre for Living with Autism (Autism CRC), Brisbane, QLD, Australia; \\ ${ }^{b}$ Griffith University, Gold Coast, QLD, Australia; ' University of Canterbury, Christchurch, New Zealand
}

\section{Keywords}

Home literacy environment - Autism - Down syndrome .

Shared book reading $\cdot$ Preschoolers

\begin{abstract}
Aims: This exploratory study investigated if there were differences in the home literacy environment of preschool children on the autism spectrum and preschool children with Down syndrome to determine if the home literacy environment may potentially be associated with strengths or weaknesses in children's social communication skills. Methods: A total of 111 parents of preschoolers with identified disabilities completed a home literacy questionnaire. Results: Results indicated that both groups of parents started reading to their children at an early age and owned at least 25 children's books. However, parents of children with Down syndrome read to their child more often, reported higher child interest in reading, and more frequently played rhyming games with their child. No group differences were found in teaching of letter names, although parents of children with autism reported a higher frequency of pointing out signs/ words in the environment and reported their children knew more letter names. Group differences were also found in the
\end{abstract}

relationship between parent behaviours, child interest, and children's print-related skills. Conclusion: This study highlights the influence both parent behaviours and child interest may have on shared book reading practices of parents with their preschool children with disabilities.

(c) 2017 S. Karger AG, Basel

\section{Introduction}

Literacy development starts long before children commence school. During the preschool years, many children show a keen interest in print, enjoy sharing books, may pretend to read books, and include literacy themes in their play [1]. During this period, often referred to as the emergent literacy stage of development, children develop important literacy foundations that are considered precursors to successful word recognition and/or reading comprehension [2]. It is well known that children with typical development who grow up in a relatively rich home literacy environment tend to be better prepared to commence formal reading instruction [3]. Less is known about the home literacy environments of preschoolers with disabilities $[4,5]$, who as a group often struggle in

\section{KARGER}

(c) 2017 S. Karger AG, Basel

E-Mail karger@karger.com

www.karger.com/fpl
Marleen Westerveld, $\mathrm{PhD}$

School of Allied Health Sciences Griffith University

Gold Coast, QLD 4222 (Australia)

E-Mail m.westerveld@griffith.edu.au 
their literacy development. Although Justice et al. [4] found that the home literacy environments of children with disabilities differed from those of children with typical development with respect to children's interest, no subgroup analysis was conducted. Considering the significant differences in communication profiles in subgroups of children with disabilities, more research is needed to better understand the relationship between children's social communication behaviour, interest in literacy-related activities, and home literacy practices. The current study aimed to address this issue by examining the parent-reported home literacy environment of preschool-age children on the autism spectrum who as a group are known to show difficulties engaging in social interactions and may have repetitive interests that do not include print-related materials, such as storybooks. Parents' responses will be compared to those provided by parents of preschoolers with Down syndrome.

\section{Emergent Literacy Skills and the Home Literacy Environment}

Children who commence formal schooling with strong emergent literacy skills are more likely to become successful readers [3, 6]. Emergent literacy skills comprise both print-related skills and meaning-related skills [7]. Printrelated skills refer to those skills that are needed for accurate and fluent word recognition and include letter name knowledge, early phonological awareness, and print concepts, such as holding the book the right way up and reading from left to right. Meaning-related skills are the skills needed for effective comprehension of written language and include vocabulary, grammar, and story retelling and comprehension skills. Emergent literacy skills generally develop during the preschool years and may be nurtured in the home or preschool environment through interactions with parents, caregivers, and early childhood professionals $[8,9]$. The home literacy environment has been conceptualised in different ways [4, 10-12], depending on the focus of the study. Within a social-constructivist framework [13], however, facilitation of early language and literacy skills within the home literacy environment is based on social interactions between the child and the parent or caregiver. Therefore, important aspects of the home literacy environment not only contain environmental factors, such as frequency of storybook reading and access to children's books, but they also rely on the child's motivation, interest in print, and oral language skills [11], although the relationship between these aspects may arguably be bidirectional. There is now strong evidence to show the importance of the home literacy environment in fostering these emergent literacy skills, and, generally speaking, children with typical development who grow up in relatively rich home literacy environments are known to perform better on emergent and early literacy-related tasks [14]. For example, research has found significant predictive correlations between parent teaching of print-related skills and alphabet knowledge during the early school years [15]. However, there is also a growing body of research demonstrating that these results do not automatically generalise to children who are at increased risk of future literacy difficulties, including children with identified language impairment $[4,8,11]$ or developmental disabilities, such as autism [16] or Down syndrome [17], and that these skills and behaviours may be differently related. These results are not surprising, considering the fact that shared book reading activities place social interaction and communication demands on both the parent and the child.

\section{Children on the Autism Spectrum}

Although literacy is not considered a core impairment associated with autism spectrum disorder, approximately $30-50 \%$ of school-aged children on the autism spectrum struggle with reading [18-20], with relative strengths observed in word recognition and weaknesses in reading comprehension [21] that persist into adolescence [22]. Only a handful of studies have investigated the early and emergent literacy pathways of children with autism [16, 23-27]. Results from these investigations clearly highlighted strengths in early print-related skills, such as letter name knowledge, and challenges in meaning-related skills, such as story retelling and comprehension skills, in line with the reader profile observed in school-age children on the autism spectrum. To help understand the emergent literacy development in young children on the autism spectrum, several potential explanations have been put forward. The most prominent line of thought with regard to their uneven emergent literacy profile is that preschoolers with autism show a cognitive tendency to focus on detail [28]. Consistent with this weak central coherence theory, children on the autism spectrum may have a particular interest in print, such as letters and environmental print, with less focus on the (meaning-related) global aspects of a story. Another explanation pertains to the children's often comorbid expressive and receptive language difficulties [29], which will particularly hinder their understanding of words and concepts used during shared book reading activities. However, it cannot be ignored that most preschoolers learn emergent literacy skills through social interaction with adults. Considering the significant challenges most children with autism show 
in sustaining social interaction, including initiating and responding to adults and peers, shared book reading in the home may not be the most preferred activity of children with autism or their parents.

Previous investigations into the home literacy environments of children on the autism spectrum have mainly compared them to those of typically developing peers, often matched for age or language ability. For example, Lanter et al. [16] reported that, based on parent report, children with autism (ages 4;1 to 7;11 [age is indicated in years;months also in the following]) were less likely to show enjoyment during shared book reading than their typical peers matched for language (ages $2 ; 7$ to $3 ; 10$ ), although there were no differences in the frequency of shared book reading, nor in the number of children's books in the home. Moreover, parents of children on the autism spectrum reported to be directly teaching their children reading and writing skills outside of shared reading on a more frequent basis. However, considering the significant differences in age between the 2 groups of children in this study [16], some of these differences in parent-reported teaching behaviours and child enjoyment may be an artefact of chronological age. In addition, the children's oral language status (i.e., disorder versus typical language development) or associated attentional difficulties may have influenced these results [30]. In other words, children's challenges with spoken language development with or without associated attentional difficulties may weaken the benefits a rich home literacy environment could have on the children's emergent literacy development. Therefore, to better understand the home literacy environment of preschoolers on the autism spectrum and the effects it may have on children's early emergent literacy skills, we chose to investigate the home literacy environment of a different group of children with developmental disabilities, namely Down syndrome.

\section{Children with Down Syndrome}

For young children with Down syndrome, the acquisition of oral language presents a number of challenges, and language deficits constitute a central characteristic of the syndrome in addition to cognitive impairment [31], although considerable variability is reported. Phonological, articulatory, motoric, and prosodic factors contribute to persistent difficulties with speech sound production and intelligibility that are almost universal [32-34]. Children with Down syndrome are slow to begin talking and to learn new words, with expressive vocabulary affected more than receptive, and syntax particularly compromised, resulting in shorter, simpler utterances with fewer different words and morphological markers $[35,36]$. Although they have delays in acquiring joint object attention [37], children with Down syndrome are reported to utilise most communicative functions consistent with their developmental level but make more use of communicative gesture relative to typically developing languageage peers and have persistent difficulties with requesting, initiating, and maintaining discourse [35, 38, 39].

There is the contemporary expectation that many children with Down syndrome will become successful readers [40-42], with literacy activities for preschoolers with Down syndrome and the home literacy environment increasingly recognised as valuable [17, 43-46]. A number of researchers have investigated the home literacy environment of children with Down syndrome, and characteristics of this environment, as well as similarities with and differences from control or comparison groups, have been reported [41, 46-48].

Shared book reading is a well-recognised aspect of the home literacy environment, so too for families of children with Down syndrome. Although clearly significant for language and literacy development, parents also identify the relational aspect of this important and authentic family behaviour, suggesting shared book reading is valued for its social communication opportunities as well [40,46, 49]. Parents of children with Down syndrome read to their children at an age and frequency comparable to that described for families of children with typical development $[50,51]$, with the majority reading to their children by age 1 year and sharing stories several times per week $[40,46,49]$. The home literacy environments of children with Down syndrome are also comparable to those of families with typically developing children with respect to the number of books in homes, indicating a dedication of resources to literacy development, although as with the wider population, a wide range and socioeconomic status (SES) differences are also reported [46, 48, 49, 51, 52]. Parents report deliberately choosing books to engage their child's interest and to teach concepts, words, and other skills [48]. While levels of interest and enjoyment are reportedly high, children with Down syndrome also experience difficulties with attention and take a relatively passive role during shared book reading [40, 49]. These difficulties may result in shorter reading sessions, abbreviated story text, and potentially more directiveness in parent language and reading behaviours $[40,48,53,54]$. As well as reading to their children, a proportion of parents reported teaching their child letter names and sounds, sight words, and drawing attention to environmental print $[46,48,49,55]$. 


\section{Research Aims}

The current research aimed to explore differences and similarities in the following 3 areas related to the home literacy environment of preschoolers with autism or Down syndrome: (a) environment: at what age do parents start reading to their child; how many children's books are in the home; how often do parents read to their children; and how do parents rate their child's interest in book reading; (b) parent behaviours: teaching letter names, pointing out signs or words in the environment, playing rhyming games; and (c) children's print-related skills in the following 3 areas: naming letters, number of letter names known, and writing ability. We also wanted to explore the correlations between parent behaviours, child interest, and children's print-related skills for each group. Our research questions were:

1. Are there differences in the home literacy environment of preschool-age children on the autism spectrum compared to their peers with Down syndrome?

2. Are there correlations between parent behaviours, child interest, and children's print-related skills for each group?

Based on previous research, we did not expect significant differences in environmental aspects, such as the age at which the parents started reading to their child or the number of books in the home [e.g., 51]. However, we hypothesised differences in the frequency of story book reading correlated with lower child interest in shared book reading by the preschool children with autism. Finally, we expected better print-related skills in the group of children on the autism spectrum.

\section{Method}

\section{Participants}

A total of 80 parents of preschool children with autism (68 boys/12 girls, mean age 57 months) completed a home literacy questionnaire. These participants were recruited for 2 different studies. The first cohort of participants with autism was recruited for a longitudinal study into the emergent literacy skills of children with autism [24]. As described in Westerveld et al. [24], a total of 57 children (ages $4 ; 0$ to $5 ; 10$ ) with autism participated. Children had a verified diagnosis of autism, had not yet started formal schooling, were able to speak in short phrases, and could partake in preschool-type activities, such as pointing to pictures. Direct assessment of these children's cognitive skills, using subtests from the Mullen Scales of Early Learning (MSEL [56]), revealed nonverbal cognitive skills (in standard scores) ranging from 44 to 119. A second group of participants with autism was recruited for a different study that investigated the effectiveness of shared book reading intervention for preschoolers with autism. A total of 23 children were recruited (ages $3 ; 3$ to $5 ; 3$ ). All children had a verified diagnosis of autism and had not yet started school. Nonverbal cognitive skills ranged from 21 to 102 on the MSEL.

Parents of children with Down syndrome were recruited into a study examining the impact of self-directed video coaching on the book-reading practices of families with children with Down syndrome [49]. The study utilised a DVD entitled Turn the Page with $\mathrm{Me}$ which was developed by the New Zealand Down Syndrome Association (NZDSA) in collaboration with an early intervention provider and is aimed at families with children from infancy to school age. Prior to receiving a complimentary copy of the DVD, participants were asked to complete a short questionnaire about their child's early literacy and how they share books with their child. Participants were recruited through NZDSA networks. Families of 60 preschool children completed the questionnaire; 31 of these 60 children were aged 3-5 years and were included in the current study ( 15 boys/16 girls, mean age 49 months). All children had a verified diagnosis of Down syndrome with no additional diagnoses reported and had not yet started formal schooling.

\section{Survey}

The parent surveys used with all 3 cohorts were based on the early literacy parent questionnaire developed by Boudreau [10]. There were some minor differences in wording of the questions between the studies, and there were differences in the number of questions asked as well as in the sequence of the questions. Furthermore, slightly different scales were used (i.e., 1-6 with parents of children with Down syndrome as opposed to $1-5$ in the other 2 studies). For the current study, questions that were used in all 3 studies and that were related to the following concepts were selected: (1) home literacy environment; (2) child interest and engagement; (3) parent behaviours; and (4) children's print-related skills. The questions are reported in the Appendix (although the wording might have been slightly different across the studies). Furthermore, all responses from the group of parents with children with Down syndrome were transformed to fit onto a 1-5 scale by combining ratings of 5 (very often) and 6 (usually) to a 5 (very often).

\section{Statement of Ethics}

Ethics approval for this project was granted by the respective Universities' Human Ethics Committees (AHS/13/14/HREC, AHS/ 34/15/HREC, and 2013/50/ERHEC), and all participants provided informed consent.

\section{Results}

\section{Data Screening and Analysis}

Because the group of children with autism was significantly older than the group with Down syndrome, correlational analyses were performed between age in months and each of the 9 variables for the groups combined, excluding "age started reading." Most of these correlations were significant, albeit low to modest (all $r<0.336$ ). We then evaluated the data to determine if they adhered to assumptions of normality, linearity, and homoscedasticity as outlined by Tabachnick and Fidell [57]. Based on 
Table 1. Home literacy environment by group

\begin{tabular}{|c|c|c|c|c|c|}
\hline \multirow[t]{2}{*}{ Survey questions } & \multicolumn{2}{|c|}{ Children with autism } & \multicolumn{2}{|c|}{ Children with Down syndrome } & \multirow[t]{2}{*}{$p$} \\
\hline & $\begin{array}{l}\text { mean }(\mathrm{SD}) \\
\text { or } n(\%)\end{array}$ & range/distribution & $\begin{array}{l}\text { mean }(\mathrm{SD}) \\
\text { or } n(\%)\end{array}$ & range/distribution & \\
\hline No. of children's books ${ }^{\mathrm{a}}$ & $3.91(1.04)$ & $2-5(10$ to $>75)$ & $3.74(1.13)$ & $1-5(0$ to $>75)$ & 0.890 \\
\hline Age starting reading, years & $2.40(1.22)$ & $1-5$ & $2.16(0.97)$ & $1-5$ & 0.338 \\
\hline From birth & & $19(24.4 \%)$ & & $8(25.8 \%)$ & \\
\hline$<1$ year & & $32(41.0 \%)$ & & $13(41.9 \%)$ & \\
\hline $1-2$ years & & $10(12.8 \%)$ & & $8(25.8 \%)$ & \\
\hline $2-3$ years & & $11(14.1 \%)$ & & $1(3.2 \%)$ & \\
\hline$>3$ years & & $6(7.7 \%)$ & & $1(3.2 \%)$ & \\
\hline Frequency of $\mathrm{SBR}^{\mathrm{b}}$ & $3.99(0.89)$ & $2-5$ & $4.74(0.51)$ & $3-5$ & $<0.001$ \\
\hline Never & $0(0 \%)$ & & & $0(0 \%)$ & \\
\hline Seldom & $4(5 \%)$ & & & $0(0 \%)$ & \\
\hline Sometimes & $20(25 \%)$ & & & $1(3.2 \%)$ & \\
\hline Often & $29(36.3 \%)$ & & & $6(19.4 \%)$ & \\
\hline Very often & $27(33.8 \%)$ & & & $24(77.4 \%)$ & \\
\hline
\end{tabular}

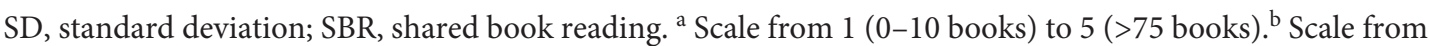
1 (never/not yet) to 5 (very often/usually).

standardised scores, no outliers were observed. The distribution of the data was evaluated for skewness or kurtosis. The only variable that was significantly skewed was question 6 ("Does your child ask for help reading words/ signs"), showing a floor effect. Based on these findings, we decided to use ANCOVAs to compare the 2 groups, entering age in months as a covariate, except when comparing the groups on question 1 - "At what age did you begin reading to your child." Effect sizes are reported as partial eta squared $\left(\mathrm{n}^{2}\right)$ and can be interpreted as small, medium, or large at values of $\mathrm{n}^{2}$ of $0.0099,0.0588$, and 0.1379 , respectively [see 58]. Some parents (11.7\%) did not respond to all questions (total $1.65 \%$ missing values). Considering the low number of missing values, these responses were considered missing data and were excluded from the analyses.

\section{Home Literacy Environment}

Table 1 provides an overview of the parents' responses to the home literacy environment questions. It was found that approximately $65 \%$ of parents started reading to their child before the age of 1 year, regardless of group, and there were no group differences. Furthermore, the majority of parents owned more than 25 children's books, and again no group differences were found. As shown in Table 1, however, significant group effects were found for frequency of book reading, with the parents of preschool children with Down syndrome reporting a higher frequency of book reading than the parents of children with autism after correcting for age $(\mathrm{F}(1,108)=14.091, p<$ $\left.0.001, \mathrm{n}^{2}=0.115\right)$.

\section{Child Interest}

As shown in Table 2, significant group differences were found in child interest in shared book reading, with the children with Down syndrome outperforming the children with autism after correcting for age $(\mathrm{F}(1,107)=$ $\left.27.661, p<0.001, \mathrm{n}^{2}=0.205\right)$. In addition, group differences were found in parents reporting that their children asked for help in reading environmental signs/words after correcting for age, but these failed to reach significance $\left(\mathrm{F}(1,107)=3.751, p=0.055, \mathrm{n}^{2}=0.034\right)$. In contrast, there were no significant group differences in parents reporting their children to independently point to or talk about pictures in the book $\left(p=0.676, \mathrm{n}^{2}=0.002\right)$.

\section{Parent Behaviours}

As shown in Table 3, there were no group differences in how often parents were teaching their children letter names $\left(p=0.695, \mathrm{n}^{2}=0.001\right)$. However, significant differences were found in parents' reported frequency of pointing out signs/words in the environment $(\mathrm{F}(1,107)=$ $26.326, p<0.001, \mathrm{n}^{2}=0.197$ ), with the parents of children with autism pointing these out more often. Significant 
Table 2. Child interest and engagement by group

\begin{tabular}{|c|c|c|c|c|c|}
\hline \multirow[t]{2}{*}{ Survey questions ${ }^{\mathrm{a}}$} & \multicolumn{2}{|c|}{ Children with autism } & \multicolumn{2}{|c|}{ Children with DS } & \multirow[t]{2}{*}{$p$} \\
\hline & mean $(\mathrm{SD})$ & range & mean $(\mathrm{SD})$ & range & \\
\hline Child interest $^{\mathrm{b}}$ & $3.19(0.89)$ & $1-5$ & $4.16(0.37)$ & $4-5$ & $<0.001$ \\
\hline Independently pointing to/talking about pictures & $3.64(0.95)$ & $1-5$ & $3.61(1.45)$ & $1-5$ & 0.676 \\
\hline Ask for help in reading words/signs & $2.22(1.36)$ & $1-5$ & $1.48(1.09)$ & $1-5$ & 0.055 \\
\hline
\end{tabular}

DS, Down syndrome; SD, standard deviation. ${ }^{\text {a }}$ Scale from 1 (never/not yet) to 5 (very often/usually). ${ }^{\text {b }}$ Scale from 1 (least favourite) to 5 (favourite).

Table 3. Parent behaviours by group

\begin{tabular}{|c|c|c|c|c|c|}
\hline \multirow[t]{2}{*}{ Survey questions ${ }^{\mathrm{a}}$} & \multicolumn{2}{|c|}{ Children with autism } & \multicolumn{2}{|c|}{ Children with DS } & \multirow[t]{2}{*}{$p$} \\
\hline & mean $(\mathrm{SD})$ & range & mean (SD) & range & \\
\hline Teach letter names & $3.30(1.21)$ & $1-5$ & $3.45(1.15)$ & $1-5$ & 0.510 \\
\hline Point out signs/words & $3.43(1.16)$ & $1-5$ & $1.97(1.20)$ & $1-5$ & $<0.001$ \\
\hline Play rhyming games & $2.04(1.01)$ & $1-4$ & $3.55(1.46)$ & $1-5$ & $<0.001$ \\
\hline
\end{tabular}

DS, Down syndrome; SD, standard deviation. ${ }^{\text {a }}$ Scale from 1 (never/not yet) to 5 (very often/usually).

Table 4. Children's print-related skills by group

\begin{tabular}{lccllll}
\hline Survey questions & \multicolumn{2}{l}{ Children with autism } & & \multicolumn{2}{l}{ Children with DS } & \multirow{2}{*}{$p$} \\
\cline { 2 - 3 } & mean (SD) & range & & mean (SD) & range & \\
\hline Names letters $^{\mathrm{a}}$ & $3.97(1.37)$ & $1-5$ & & $2.45(1.50)$ & $1-5$ & 0.510 \\
Writes words $^{\mathrm{a}}$ & $1.95(1.13)$ & $1-5$ & & $1.61(1.26)$ & $1-5$ & 0.857 \\
No. of letter names & $18.95(10.04)$ & $0-26$ & & $4.34(7.49)$ & $0-26$ & $<0.001$ \\
\hline
\end{tabular}

DS, Down syndrome; SD, standard deviation. ${ }^{\text {a }}$ Scale from 1 (never/not yet) to 5 (very often).

group differences were also found when asking if parents played rhyming games with their children, with the parents of children with Down syndrome reporting a higher frequency of this behaviour $(\mathrm{F}(1,106)=30.621, p<0.001$, $\left.\mathrm{n}^{2}=0.224\right)$.

\section{Children's Print-Related Skills}

As shown in Table 4, there were significant group differences in the reported preschoolers' frequency of naming letters, with the children with autism outperforming the children with Down syndrome $(\mathrm{F}(1,105)=19.526$, $\left.p<0.001, \mathrm{n}^{2}=0.157\right)$. The preschoolers on the autism spectrum also knew significantly more letter names, with a large effect size $\left(\mathrm{F}(1,99)=47.063, p<0.001, \mathrm{n}^{2}=0.322\right)$. No significant group differences were found in children's reported ability to write words, although floor effects were noted, with $74 \%$ of children with Down syndrome and $49 \%$ of children with autism obtaining a score of 1 (not yet/never).

\section{Correlations between Parent Behaviours, Child}

Interest, and Children's Print-Related Skills by Group

To answer our second research question, we investigated correlations (using Spearman rank order) between parent behaviour, child interest, and children's print-related skills by group. To determine if these correlations 
Table 5. Correlations between children's age, parent behaviours, child interest, and children's print-related skills for each group

\begin{tabular}{|c|c|c|c|c|c|c|c|c|c|c|c|}
\hline \multicolumn{12}{|c|}{ Children with autism } \\
\hline 1 & Child's age in months & - & -0.111 & 0.046 & -0.210 & -0.028 & 0.020 & 0.121 & -0.012 & -0.041 & 0.195 \\
\hline 2 & Parent teaches LNK & & - & $0.350^{* *}$ & 0.075 & 0.178 & 0.198 & 0.193 & $0.397^{* *}$ & $0.378^{* *}$ & 0.155 \\
\hline 3 & Parent points out signs/words & & & - & -0.015 & -0.012 & 0.182 & $0.482^{* *}$ & $0.292^{* *}$ & 0.064 & $0.306^{* *}$ \\
\hline 4 & Parent plays rhyme games & & & & - & 0.091 & 0.082 & 0.146 & -0.100 & -0.134 & 0.003 \\
\hline & pictures & & & & & & - & $0.349^{* *}$ & 0.092 & -0.016 & 0.216 \\
\hline 7 & Child asks for help reading & & & & & & & & & & \\
\hline & words & & & & & & & - & $0.310^{* *}$ & 0.181 & $0.456^{* *}$ \\
\hline 8 & Child names letters & & & & & & & & - & $0.844^{* *}$ & $0.548^{* *}$ \\
\hline 9 & Child's LNK & & & & & & & & & - & $0.394^{* *}$ \\
\hline 10 & Child writes words & & & & & & & & & & - \\
\hline 3 & Parent points out signs/words & & & - & $0.449^{*}$ & 0.220 & 0.222 & 0.335 & $0.558^{* *}$ & $0.519 *$ & 0.044 \\
\hline 4 & Parent plays rhyme games & & & & - & $0.457^{*}$ & $0.602^{* *}$ & 0.183 & $0.579^{* *}$ & $0.593^{* *}$ & 0.235 \\
\hline 5 & Child interest in books & & & & & - & $0.375^{*}$ & 0.007 & $0.379^{*}$ & 0.365 & 0.204 \\
\hline \multicolumn{12}{|c|}{6 Child points to/talks about } \\
\hline & pictures & & & & & & - & 0.071 & $0.461^{* *}$ & $0.503^{* *}$ & 0.077 \\
\hline \multirow[t]{2}{*}{7} & Child asks for help reading & & & & & & & & & & \\
\hline & words & & & & & & & - & 0.253 & 0.253 & 0.254 \\
\hline 8 & Child names letters & & & & & & & & - & $0.968^{* *}$ & $0.475^{* *}$ \\
\hline 9 & Child's LNK & & & & & & & & & - & $0.541^{* *}$ \\
\hline & Child writes words & & & & & & & & & & - \\
\hline
\end{tabular}

LNK, letter name knowledge in number of letters; DS, Down syndrome. ${ }^{*} p<0.05 ;{ }^{* *} p<0.01$.

should correct for children's age in months, we first included age in months as a variable. The only variable that was significantly correlated with age in months was "child writes words" ( $r=0.637, p<0.001)$ for the children with Down syndrome. We, therefore, decided not to include age as a covariate in the analyses. As shown in Table 5, observable differences were found between the 2 groups on the parents' reported use of rhyme games and its correlations with other parent and child behaviours. For the group of children with Down syndrome, parents' reported frequency of playing rhyme games was significantly correlated with other parent behaviours as well as their child's interest in shared book reading and pictures and their child's letter name knowledge. In contrast, parent behaviour related to playing rhyme games showed no statistically significant correlations with other parent book reading behaviours in the group of children with autism, nor with their children's interest or the children's printrelated skills.

Home Literacy Environment

\section{Discussion}

The importance of a rich home literacy environment for stimulating language development and emergent literacy skills in preschool-age children has been well established. It is concerning, therefore, that the home literacy environments of children with disabilities have been reported to be qualitatively different from those of children who demonstrate typical development [4]. However, few studies have investigated subgroups of children with disabilities. This study addressed this shortcoming and compared and contrasted the home literacy environments of preschoolers with autism and preschoolers with Down syndrome using a home literacy parent questionnaire.

Consistent with our hypothesis, our data confirm that shared book reading is an authentic family behaviour for families of preschool children with autism and Down syndrome, and the majority of homes contained more than 25 children's books. Families of children with autism 
and Down syndrome begin to read to their children from an early age; however, the children with Down syndrome in our study were read to more often than the children on the autism spectrum (after correcting for age). This finding seems in contrast to the findings reported recently by Justice et al. [4], who found no differences in the home literacy environment of children with and without disabilities with respect to the frequency of shared book reading. In our opinion, the difference in the reading frequency between the participant cohorts in the present study may reflect a deliberate parent focus as well as emphasis from professionals and interest/support groups. Unlike autism, Down syndrome is typically diagnosed at or even before birth; thus, parent behaviours and provision of the home literacy environment in their child's preschool years are informed by at least some knowledge of the language and literacy challenges their child may experience. In New Zealand, support from an early intervention team, including a speech-language therapist, is provided to families of children with Down syndrome from birth or early infancy [59], and a considerable amount of targeted and online information emphasises language and literacy development for these children [60]. By contrast, early literacy development of children on the autism spectrum may not be of particular concern to parents and/or early intervention providers [61], resulting in less emphasis on literacy-related skills by early intervention professionals during the preschool years for this population.

Our results indicated that children on the autism spectrum displayed significantly lower interest in shared book reading compared to other activities than the children with Down syndrome. To help explain these findings, the influence and role of the child in the shared book reading process must be considered, as well as the bidirectional influence on the parent and child language during story reading [62]. Although an official autism diagnosis does not typically occur until the age of 3 or 4 years (see Gillon et al. [63]), these children's atypical language development and social interaction difficulties may already be impacting shared book reading frequency earlier, and delays in communication and language are reported well before a diagnosis of autism spectrum disorder is received [64]. Furthermore, children with autism often have stereotypical interests that may not include sharing of books. Conversely, there is a belief that people with Down syndrome are especially sociable, possibly based on their higher attention to people rather than objects $[65,66]$ and compatible with the finding that interactions may be more positive for mothers and their child with Down syn- drome than for mothers and their child with other developmental disabilities [67].

Interestingly, there were no group differences in how often parents reported teaching their children letter names, despite the fact that the children on the autism spectrum knew more letter names than their peers with Down syndrome. These findings are consistent with previous studies showing particular strengths in print-related emergent literacy skills, such as letter identification, in young children with autism [26] and imply that these skills may not be directly a result of parent teaching. Our results also showed that parents of children with autism were more likely to point out signs/words in the environment, even after correcting for age, which suggests that parents may be sensitive to their children's strengths and focus of attention. To try and disentangle the relationships between parent behaviours, child interest, and children's print-related skills, we investigated correlations between these factors for each group of children. Observable group differences were found in the parents' reported use of rhyme games, with the parents of preschoolers with Down syndrome reporting to engage in this activity more often. Moreover, for the group of children with Down syndrome, parents' reported frequency of playing rhyme games was significantly correlated with other parent behaviours as well as their child's interest in shared book reading and pictures and their child's letter name knowledge. In contrast, for the preschoolers with autism, parent behaviour related to playing rhyme games showed no correlations with other parent book reading behaviours, nor with their children's interest in book reading or the children's print-related skills. Taking into consideration that the parents of children with autism reported lower use of rhyming games, our results seem to suggest that this language-based parent-child activity is tapping into children's motivation for social interaction and communication, impairments that are core deficits in autism.

\section{Limitations and Future Directions}

The results from this study used data from 3 cohorts of children who were recruited for different studies. Although the measures were the same, we had to control for age, as the children with autism were older than the children with Down syndrome. Data on the home literacy environment in the current study were gathered via parent report rather than direct assessment. Although previous research has found good correlations between parent report and children's print-related literacy skills [26, 49], nonetheless, there is potential for bias towards responses perceived to be more favourable. SES has been shown to 
impact home literacy environments and literacy behaviours [46, 52]; however, SES was not explored in this study. Regardless, both the children with Down syndrome and the children with autism were recruited from a range of SES. The inclusion criteria for the children with autism excluded children with severe cognitive impairments, and we did not collect direct child data on nonverbal cognition for the children with Down syndrome. We also did not measure children's social communication skills but made assumptions based on the children's diagnosis. Future research should consider recruiting cohorts of children from diagnosis to school entry, without exclusion criteria, containing parent-report measures of social communication and ensuring a range of SES is included to better understand the relationship between parent behaviour, children's developmental level, and children's emergent literacy skill development.

\section{Conclusions}

In summary, our results show the importance of taking several aspects of the home literacy environment of children with disabilities into consideration, including child interest as well as parent and child behaviours. An improved understanding of the interplay between child interest, parent and child behaviours, as well as strengths or weaknesses in social communication has the potential to influence intervention practices.

\section{Acknowledgements}

The authors wish to thank the families for taking the time to complete these surveys. We are grateful to Janette Over for entering all the results into the database. The first author acknowledges the financial support of the Cooperative Research Centre for Living with Autism, established and supported under the Australian Government's Cooperative Research Centres Program.

\section{Disclosure Statement}

The authors have no conflicts of interest to declare.

\section{Appendix}

Survey Questions

\section{Home literacy environment \\ $1 \quad$ At what age did you begin reading to your child? \\ 2 How often do you read to your child?a \\ 3 How many books does your child own?}

\section{Child interest and motivation}

4 In comparison to other activities, how would you rate your child's interest in books? (1-5 scale from least favourite to favourite activity)

5 Does your child independently point to or talk about pictures when you read stories? ${ }^{\mathrm{a}}$

6 Does your child ask for help in reading words, such as signs on the street or words on food packages? ${ }^{\mathrm{a}}$

Parent teaching of print-related skills

7 Do you attempt to teach the names of the letters in the alphabet and/or alphabet sounds when reading?

8 Do you point out signs and words, such as restaurant names or street signs to your child (i.e., McDonalds' arches, Pepsi logo, etc.)? ${ }^{a}$

9 Do you play rhyming games with your child?a

\section{Children's print-related skills}

10 Does your child name letters of the alphabet? (such as pointing to the letter " $A$ " when you ask him/her to?) ${ }^{\mathrm{a}}$

11 If yes, how many letters does your child know?

12 Does your child write words? ${ }^{\mathrm{a}}$

a A scale of 1 (never/not yet) to 5 (very often/usually) was used for these questions.

\section{References}

Home Literacy Environment

\footnotetext{
1 Justice LM, Bowles RP, Skibbe LE: Measuring preschool attainment of print-concept knowledge: a study of typical and at-risk 3- to 5year-old children using item response theory. Lang Speech Hear Serv Sch 2006;37:224-235.

2 National Reading Panel: Teaching Children to Read: An Evidence-Based Assessment of the Scientific Research Literature on Reading and Its Implications for Reading Instruction. Washington, DC, US Government Printing Office, 2000.
}

3 Lonigan CJ, Purpura DJ, Wilson SB, Walker PM, Clancy-Menchetti J: Evaluating the components of an emergent literacy intervention for preschool children at risk for reading difficulties. J Exp Child Psychol 2013;114:111130.

4 Justice LM, Logan JAR, Ișitan S, Saçkes M: The home-literacy environment of young children with disabilities. Early Child Res Q 2016;37:131-139. 
5 Carlson E, Bitterman A, Jenkins F: Home literacy environment and its role in the achievement of preschoolers with disabilities. J Spec Educ 2012;46:67-77.

6 Tunmer WE, Chapman JW, Prochnow JE: Literate cultural capital at school entry predicts later reading achievement: a seven year longitudinal study. New Zeal J Educ Stud 2006; $41: 183-204$.

7 Whitehurst GJ, Lonigan CJ: Child development and emergent literacy. Child Dev 1998 69:848-872.

8 Pentimonti JM, Zucker TA, Justice LM, Petscher Y, Piasta SB, Kaderavek JN: A standardized tool for assessing the quality of classroom-based shared reading: Systematic Assessment of Book Reading (SABR). Early Child Res Q 2012;27:512-528.

9 Sénéchal M, Pagan S, Lever R, Ouellette GP: Relations among the frequency of shared reading and 4-year-old children's vocabulary, morphological and syntax comprehension, and narrative skills. Early Educ Dev 2008;19: 27-44.

10 Boudreau D: Use of a parent questionnaire in emergent and early literacy assessment of preschool children. Lang Speech Hear Serv Sch 2005;36:33-47.

-11 Sawyer BE, Justice LM, Guo Y, Logan JAR, Petrill SA, Glenn-Applegate K, et al: Relations among home literacy environment, child characteristics and print knowledge for preschool children with language impairment. J Res Read 2014;37:65-83.

12 Brown ML, Westerveld MF, Gillon GT: Early storybook reading with babies and young children: parents' opinions and home reading practices. Aust J Early Child 2017;42:69-77.

13 Vygotsky LS: Mind and Society: The Development of Higher Psychological Processes. Cambridge, MA, Harvard University Press, 1978.

14 Sénéchal M, LeFevre J: Parental involvement in the development of children's reading skill: a five-year longitudinal study. Child Dev 2002;73:445-460.

15 Sénéchal M: Testing the home literacy model: parent involvement in kindergarten is differentially related to grade 4 reading comprehension, fluency, spelling, and reading for pleasure. Sci Stud Read 2006;10:59-87.

16 Lanter E, Freeman D, Dove S: Procedural and conceptual print-related achievements in young children with autism spectrum disorders. Focus Autism Other Dev Dis 2013;28: $14-25$.

17 Ricci LA: Exploration of reading interest and emergent literacy skills of children with Down syndrome. Int J Spec Educ 2011;26:80-91.

18 Henderson LM, Clarke PJ, Snowling MJ: Reading comprehension impairments in autism spectrum disorders. Annee Psychol 2014;114:779-797.

19 Nation K, Clarke P, Wright B, Williams C: Patterns of reading ability in children with autism spectrum disorder. J Autism Dev Disord 2006;36:911-919.
20 Arciuli J, Stevens K, Trembath D, Simpson IC: The relationship between parent report of adaptive behavior and direct assessment of reading ability in children with autism spectrum disorder. J Speech Lang Hear Res 2013; 56:1837-1844.

21 Huemer SV, Mann V: A comprehensive profile of decoding and comprehension in autism spectrum disorders. J Autism Dev Disord 2010;40:485-493.

22 Ricketts J, Jones CG, Happé F, Charman T: Reading comprehension in autism spectrum disorders: the role of oral language and social functioning. J Autism Dev Disord 2013;43: 807-816.

23 Jacobs DW, Richdale AL: Predicting literacy in children with a high-functioning autism spectrum disorder. Res Dev Disabil 2013;34: 2379-2390.

24 Westerveld MF, Paynter J, Trembath D, Webster AA, Hodge AM, Roberts J: The emergent literacy skills of preschool children with autism spectrum disorder. J Autism Dev Disord 2017:47:424-438.

25 Dynia JM, Lawton K, Logan JAR, Justice LM: Comparing emergent-literacy skills and home-literacy environment of children with autism and their peers. Top Early Child Spec Educ 2014;34:142-153.

26 Lanter E, Watson LR, Erickson KA, Freeman D: Emergent literacy in children with autism: an exploration of developmental and contextual dynamic processes. Lang Speech Hear Serv Sch 2012;43:308-324.

27 Davidson MM, Ellis Weismer S: Characterization and prediction of early reading abilities in children on the autism spectrum. J Autism Dev Disord 2014;24:828-845.

28 Happé F, Frith U: The weak coherence account: detail-focused cognitive style in autism spectrum disorders. J Autism Dev Disord 2006;36:5-25.

29 Tager-Flusberg H, Paul R, Lord C: Language and communication in autism; in Cohen DJ, Volkmar FR (eds): Handbook of Autism and Pervasive Developmental Disorders, ed 3. New York, John Wiley and Sons, 2005, pp 335-364.

30 McGinty AS, Justice LM: Predictors of print knowledge in children with specific language impairment: experiential and developmental factors. J Speech Lang Hear Res 2009;52:8197.

31 Cleland J, Wood S, Hardcastle W, Wishart J, Timmins C: Relationship between speech, oromotor, language and cognitive abilities in children with Down's syndrome. Int J Lang Commun Disord 2010;45:83-95.

32 Kent RD, Voperian HK: Speech impairment in down syndrome: a review. J Speech Lang Hear Res 2013;56:178-210.

33 Kumin L: Speech intelligibility and childhood verbal apraxia in children with Down syndrome. Downs Syndr Res Pract 2006;10:1022.
34 Rupela V, Velleman S, Andrianopolous M: Motor speech skills in children with Down syndrome: a descriptive study. Int J Speech Lang Pathol 2016;18:483-492.

35 Martin G, Klusek J, Estigarribia B, Roberts J: Language characteristics of individuals with Down syndrome. Top Lang Disord 2009;29: 112-132.

36 Roberts J, Price J, Malkin C: Language and communication development in Down syndrome. Ment Retard Dev Disabil Res Rev 2007;13:26-35

37 Adamson LB, Bakeman R, Deckner DF, Romski MA: Joint engagement and the emergence of language in children with autism and Down syndrome. J Autism Dev Disord 2009; 39:84-96.

38 Roberts J, Martin GE, Moskowitz L, Harris AA, Foreman J, Nelson L: Discourse skills of boys with fragile $\mathrm{X}$ syndrome in comparison to boys with Down syndrome. J Speech Lang Hear Res 2007;50:475-492.

39 van Bysterveldt A, Westerveld MF, Gillon G, Foster-Cohen S: Personal narrative skills of school-aged children with Down syndrome. Int J Lang Commun Disord 2012;47: 95-105.

40 Ricci LA, Osipova A: Visions for literacy: parents' aspirations for reading in children with Down syndrome. Br J Spec Educ 2012;39: 123-129.

41 van Bysterveldt A, Gillon G, Foster-Cohen $S$ : Literacy environments for children with Down syndrome: what's happening at home? Downs Syndr Res Pract 2010;12:98102.

42 Trenholm B, Mirenda P: Home and literacy experiences of individuals with Down syndrome. Downs Syndr Res Pract 2006;10:3040.

43 van Bysterveldt A, Gillon G, Moran C: Enhancing phonological awareness and letter knowledge in preschool children with Down syndrome. Intl J Disabil Dev Educ 2006;53: 301-329.

44 van Bysterveldt A, Gillon G, Foster-Cohen S: Integrated speech and phonological awareness intervention for pre-school children with Down syndrome. Int J Lang Commun Disord 2010;4:320-335.

45 Colozzo P, McKeil L, Petersen JM, Szabo A An early literacy program for young children with Down syndrome: changes observed over one year. J Policy Pract Intellect Disabil 2016; 13:102-110.

46 Al Otaiba S, Lewis S, Whalon K, Dyrlund A, McKenzie A: Home literacy environments of young children with Down syndrome: findings from a web-based survey. Remedial Spec Educ 2009;30:96-107.

47 Ricci LA: Home literacy environments, interest in reading and emergent literacy skills of children with Down syndrome versus typical children. J Intellect Disabil Res 2011;55:596609 
48 van Heerden C, Kritzinger A: Parental perceptions and practices of emergent literacy development in young children with Down syndrome: the development of intervention guidelines. S Afr J Commun Disord 2008;55: 51-68.

49 van Bysterveldt A, Foster-Cohen S, Gillon GT: Engaging families in promoting emergent literacy for children with Down syndrome; in Kreider H, Caspe M, Hiatt-Michael DB (eds): Promising Practices for Engaging Families in Literacy. Charlotte, NC, Information Age Publishing, 2013, pp 29-41.

50 Roberts J, Jurgens J, Burchinal M: The role of home literacy practices in preschool children's language and emergent literacy skills. J Speech Lang Hear Res 2005;48:345-59.

-51 Butz AM, Crocetti M, Thompson RE, Lipkin $\mathrm{PH}$ : Promoting reading in children: do reading practices differ in children with developmental problems? Clin Pediatr (Phila) 2008; 48:275-283.

52 Neumann M: A socioeconomic comparison of emergent literacy and home literacy in Australian preschoolers. Eur Early Child Educ Res J 2016;24:555-566.

53 Schneider P, Hecht BF: Interaction between children with developmental delays and their mothers during a book-sharing activity. Intl J Disabil Dev Educ 1995;42:44-56.
54 Jordan S, Miller G, Riley K: Enhancements of dialogic reading for young children with Down's syndrome. Young Except Child 2011; 14:19-30.

55 Sénéchal M, LeFevre J: Storybook reading and parent teaching: links to language and literacy development. New Dir Child Adolesc Dev 2001;92:39-52

56 Mullen EM: Mullen Scales of Early Learning. Circle Pines, MN, American Guidance Service, 1995.

57 Tabachnick BG, Fidell LS: Using Multivariate Statistics. Boston, MA, Pearson, 2013.

58 Richardson JTE: Eta squared and partial eta squared as measures of effect size in educational research. Educ Res Rev 2011;6:135147.

59 Ministry of Health: The Clinical Assessment and Management of Children, Young People and Adults with Down Syndrome. Wellington, New Zealand, Ministry of Health, 2001.

60 Down Syndrome Education International. 2017. https://www.dseinternational.org/en$\mathrm{gb} /$.

61 Westerveld MF, Paynter J, Trembath D: Reading instruction for children with ASD: getting the story straight. J Clin Pract Speech Lang Pathol 2016;18:80-83.
62 Deckner DF, Adamson LB, Bakeman R: Child and maternal contributions to shared reading: effects on language and literacy development. J Appl Dev Psychol 2006;27:31-41.

63 Gillon G, Hyter Y, Dreux F, Ferman S, Hus Y, Petinou K, Segal O, Tumarova T, Vogindroukas I, Westby C, Westerveld M: International survey of speech-language pathologists' practices in working with children with autism spectrum disorder. Folia Phoniatr Logop 2017;69:8-19.

64 Mitchell S, Brian J, Zwaigenbaum L, Roberts W, Szatmari P, Smith I, et al: Early language and communication development of infants later diagnosed with autism spectrum disorder. J Dev Behav Pediatr 2006;27:S69-S78.

65 Adamson LB, Deckner DF, Bakeman R: Early interests and joint engagement in typical development, autism, and Down syndrome. J Autism Dev Disord 2010;40:665-676.

66 Slonims V, McConachie H: Analysis of mother-infant interaction in infants with Down syndrome and typically developing infants. Am J Ment Retard 2006;111:273-289.

67 Mitchell DB, Hauser-Cram P, Crossman MK: Relationship dimensions of the "Down syndrome advantage". J Intellect Disabil Res 2015;59:506-518. 